\title{
Primary research \\ Comparison of APACHE II, MEES and Glasgow Coma Scale in patients with nontraumatic coma for prediction of mortality Štefek Grmec ${ }^{\star}$ and Vladimir Gašparovic ${ }^{\dagger}$
}

\author{
*Emergency Medical Service, Maribor Teaching Hospital, Ljubljanska, Slovenia \\ +University Department of Internal Medicine, Emergency and Intensive Care Medicine, Kispaticena, Rebro, Zagreb, Croatia
}

Correspondence: Štefek Grmec, MD, MSc, EMS-PHU, Maribor Teaching Hospital, Ljubljanska 5, MIS-2000, Slovenia. Tel: +386 23211234 ; fax: +386 2320 2315; e-mail: grmec-mis@sur.net

Received: 11 July 2000

Revisions requested: 22 September 2000

Revisions received: 10 October 2000

Accepted: 6 November 2000

Published: 14 December 2000
Critical Care 2001, 5:19-23

(C) 2001 Grmec and Gašparovic, licensee BioMed Central Ltd (Print ISSN 1364-8535; Online ISSN 1466-609X)

\begin{abstract}
Introduction: There are numerous prehosital descriptive scoring systems, and it is uncertain whether they are efficient in assessing of the severity of illness and whether they have a prognostic role in the estimation of the illness outcome (in comparison with that of the prognostic scoring system Acute Physiology and Chronic Health Evaluation [APACHE] II). The purpose of the present study was to assess the value of the various scoring systems in predicting outcome in nontraumatic coma patients and to evaluate the importance of mental status measurement in relation to outcome.
\end{abstract}

Patients and methods: In a prehospital setting, postintervention values of the Mainz Emergency Evaluation System (MEES) and Glasgow Coma Scale (GCS) were measured for each patient. The APACHE II score was recorded on the day of admission to the hospital. This study was undertaken over a 2-year period (from January 1996 to October 1998), and included 286 consecutive patients (168 men, 118 women) who were hospitalized for nontraumatic coma. Patients younger than 16 years were not included. Their age varied from 16 to 87 years, with mean \pm standard deviation of $51.8 \pm 16.9$ years. Sensitivity, specificity and correct prediction of outcome were measured using the $\chi^{2}$ method, with four severity scores. The best cutoff point in each scoring system was determined using the Youden index. The difference in Youden index was calculated using the $Z$ score. For each score, the receiver operating characteristic (ROC) curve was obtained. The difference in ROC was calculated using the $\mathrm{Z}$ score. $P<0.05$ was considered statistically significant.

Results: For prediction of mortality, the best cutoff points were 19 for APACHE II, 18 for MEES and 5 for GCS. The best cutoffs for the Youden index were 0.63 for APACHE II, 0.61 for MEES and 0.65 for GCS. The correct prediction of outcome was achieved in 79.9\% for APACHE II, 78.3\% for MEES and $81.9 \%$ for GCS. The area under the ROC curve (mean \pm standard error) was $0.86 \pm 0.02$ for APACHE II, $0.84 \pm 0.06$ for MEES and $0.88 \pm 0.03$ for GCS. There were no statistically significant differences among APACHE II, MEES and GCS scores in terms of correct prediction of outcome, Youden index or area under ROC curve.

Conclusions: APACHE II is not much better than prehospital descriptive scoring systems (MEES and GCS). APACHE II and MEES should not replace GCS in assessment of illness severity or in prediction of mortality in nontraumatic coma. For the assessment of mortality, the GCS score provides the best indicator for these patients (simplicity, less time-consuming and effective in an emergency situation.

Keywords: Acute Physiology and Chronic Health Evaluation II, Glasgow Coma Scale, Mainz Emergency Evaluation System, nontraumatic coma, prediction of mortality

$\mathrm{APACHE}=$ Acute Physiology and Chronic Health Evaluation; GCS = Glasgow Coma Scale; MEES = Mainz Emergency Evaluation System; $\mathrm{ROC}=$ receiver operating characteristic. 


\section{Introduction}

There is growing interest in intensive care medicine in scoring systems for measuring the severity of illness and predicting outcome in critically ill patients. Since 1974, the GCS [1] has been routinely applied in intensive care units and emergency prehospital settings. The GCS provides a good basis for assessing the depth of consciousness and coma. This scale, together with other neurological assessments [2-5], should be administered as soon as possible in emergency situations, and may be repeated at intervals, especially when neurological function is fluctuating [6].

The GCS was developed as a means for grading patients with traumatic brain injury and for predicting their chances of neurological recovery. Clinicians now use GCS as the only neurological predictor in many prognostic systems, such as APACHE, APACHE II, APACHE III, Acute Physiology Score (APS) and Simplified Acure Physiology Score (SAPS) [4,7-11]. The MEES is a descriptive scoring system that includes the GCS assessment [12]. In theory, the prognostic APACHE $\|$ and the descriptive MEES scoring systems are more relevant to prediction of outcome in critically ill patients because the GCS assessment is included in these systems. On the basis of other parameters (arterial pressure, heart rate, respiratory rate, oxygenation, chronic health points, age points), the MEES (descriptive) and APACHE II (prognostic) systems should be better than the GCS at predicting outcomes.

The purpose of the present study was to assess the value of scoring systems in predicting outcome in nontraumatic coma patients and to evaluate the importance of mental status measurement in relation to outcome.

\section{Patients and methods}

This prospective study was undertaken over a 2-year period, and included 286 consecutive patients hospitalized for nontraumatic coma. The inclusion criteria were GCS $\leq 9$, and specific medical diagnoses as follows: hypoxic or ischaemic injury; focal cerebral injury; general cerebral injury; metabolic or septic encephalopathy; and drug-induced coma or toxic injury, including drug overdose and coma persisting $24 \mathrm{~h}$ after discontinuation of toxic substances.

In the prehospital setting, postintervention values (before admission of the patient to hospital) for the MEES and GCS scales were measured in each patient (Table 1). The APACHE II score was recorded on the day of admission to hospital [7].

The sensitivity, specificity and predictive power of each cutoff point were calculated from the two-by-two table in SPSS for Windows (Mlcrosoft, Washington, USA) for APACHE II, MEES and GCS [14]. The Youden index was also used to determine the best cutoff points (the higher
Table 1

\begin{tabular}{|c|c|}
\hline Parameter & Score \\
\hline \multicolumn{2}{|l|}{ GCS } \\
\hline 15 & 4 \\
\hline $12-14$ & 3 \\
\hline $8-11$ & 2 \\
\hline$\leq 7$ & 1 \\
\hline \multicolumn{2}{|l|}{ Pulse rate (beats/min) } \\
\hline $60-100$ & 4 \\
\hline $50-59$ or $101-130$ & 3 \\
\hline $40-49$ or $131-160$ & 2 \\
\hline$\leq 39$ or $\geq 161$ & 1 \\
\hline \multicolumn{2}{|l|}{ Respiration rate (breaths/min) } \\
\hline $12-18$ & 4 \\
\hline $8-11$ or $19-24$ & 3 \\
\hline $5-7$ or $25-30$ & 2 \\
\hline$\leq 4$ or $\geq 31$ & 1 \\
\hline \multicolumn{2}{|l|}{ Electrocardiogram } \\
\hline Sinus rhythm & 4 \\
\hline SVES, VES & 3 \\
\hline Absolute arrhythmia; polymorphic VES & 2 \\
\hline Ventricular tachycardia, ventricular fibrillation, asystole & 1 \\
\hline \multicolumn{2}{|l|}{ Systolic blood pressure $(\mathrm{mmHg})$} \\
\hline $120-140$ & 4 \\
\hline $100-119$ or $141-159$ & 3 \\
\hline $80-99$ or $160-229$ & 2 \\
\hline$\leq 79$ or $\geq 230$ & 1 \\
\hline \multicolumn{2}{|l|}{ Arterial oxygen saturation } \\
\hline$\geq 96$ & 4 \\
\hline $91-95$ & 3 \\
\hline $86-90$ & 2 \\
\hline$\leq 85$ & 1 \\
\hline \multicolumn{2}{|l|}{ Pain } \\
\hline None & 4 \\
\hline Mild & 3 \\
\hline Severe & 2 \\
\hline
\end{tabular}

The maximum score is 28 ; the minimum is 10 . SVES, supraventricular premature contractions; VES, premature ventricular contractions.

the index, the better the prediction at the cutoff point) [15]. Percentages of correct predictions of mortality were obtained at these same cutoff points. For each score, ROC curves were obtained [16,17]. The ROC curve depicts the relation between true-positive results (number of predicted deaths among those who actually died) and false-positive results (number of predicted deaths among those who actually survived) for each score. The greater the area under ROC curve, the better the scoring system. The ROC curve was calculated using the Systat software (Systat Inc, Evanstan, IL, USA). The outcome predictions data were analyzed using McNemar's test. The comparasions of the areas under the ROC curves and the analyses of the differences of Youden index were performed using the method described by Hanley and McNeil $[16,17]$. $P<0.05$ was considered statistically significant. Values are expressed as mean \pm standard error. 


\section{Results}

Of the 286 patients included in the present study, 80 died in hospital. The patients who died were older than those who survived (66.8 \pm 11.1 years versus $46.1 \pm 15.4$ years; $P<0.05)$ and a higher proportion were males $(61 \%)$. The scores for all three scales were better in survivors than in those who died (APACHE II, $29.8 \pm 5.3$ versus $20.8 \pm 2.8$ $[P<0.05]$; MEES, $16.2 \pm 2.5$ versus $20.1 \pm 2.7[P<0.05]$; GCS, $\quad 6.2 \pm 2.1$ versus $8.1 \pm 1.2 \quad[P<0.05])$. The distributions of APACHE II, MEES and GCS scores are given in Fig. 1.

Hypoxic or ischaemic injury was the cause of coma in 62 $(21.7 \%)$, metabolic or septic coma occurred in 45 (15.7\%), focal cerebral lesions occurred in 56 (19.6\%), generalized cerebral lesions occurred in 22 (7.7\%), and drug-induced or toxic coma occurred in 101 (35.3\%). Mortality data are given in Table 2.

Table 3 provides data for sensitivity, specificity and correct predictions of outcome at the cutoff points that gave the best Youden index. The three scores were also compared by drawing ROC curves in order to avoid fixing arbitrary cutoff points (Fig. 2). There were no statistically significant differences in the correct prediction of outcome, Youden index or area under the ROC curve among APACHE II, MEES and GCS for hospital mortality.

\section{Discussion}

Subjective evaluations of clinical status by individual clinicians may differ in terminology, and even in measurement of the severity of illness. Hence, various descriptive and prognostic evaluation scales (scoring systems) have been developed during the past three decades. Objective evaluation of clinical status would facilitate comparison of methods, staff, clinical centres and studies $[1-8,13,14]$. The need for such evaluation scales is particularly evident in coma patients, and even more so in patients with alterations in consciousness. The aim of research in this area is to obtain a reliable and sensitive scale.

In 1974 , such research resulted in the GCS $[1,6]$. Since this scale was reported, numerous studies have examined its value in assessing clinical status and prognosis. Initially, the scale was used in patients with head injury [6], but later it became widely used in evaluating central nervous system lesions and state of consciousness.

With the development of emergency medicine, a need arose for evaluation scales that would provide rapid triage and objective status assessment. On the other hand, a prehospital evaluation scale would be optimal if (apart from being descriptive) it had a prognostic component, and would therefore be applicable to hospital-based observation of the patient. Among the various scales,
Figure 1
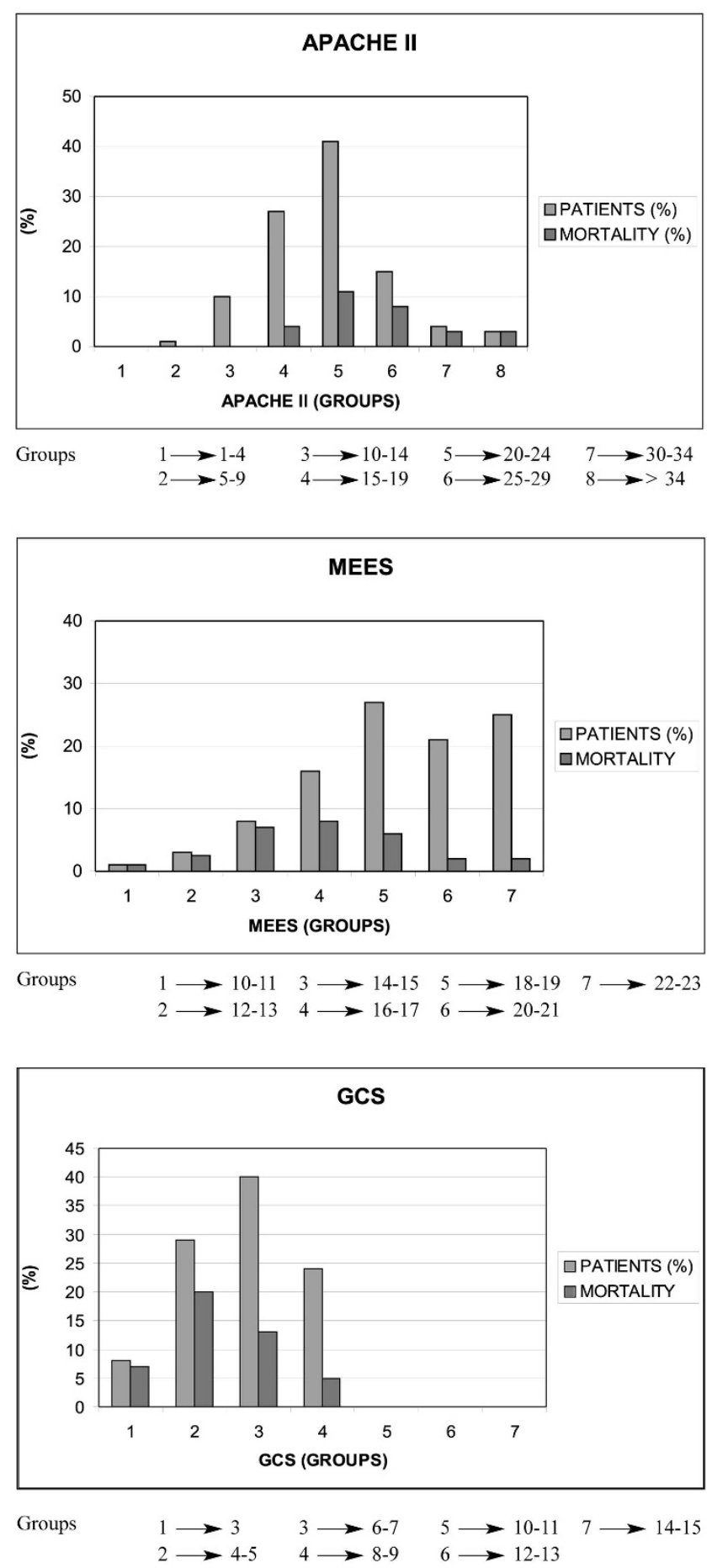

Distribution of patients by APACHE II, MEES and GCS scores.

MEES has attracted attention because of its applicability in trauma and illness [12]. Cho and Wang [14] concluded that, for head-injured patients, the GCS has good predictive value for hospital mortality in comparison with other 
Table 2

\begin{tabular}{lccc}
\multicolumn{4}{l}{ Outcomes after nontraumatic coma and coma aetiology } \\
\hline Coma aetiology & $n(\%)$ & $\begin{array}{c}\text { Survival } \\
\text { rate }(n[\%])\end{array}$ & $\begin{array}{c}\text { Mortality } \\
\text { rate }(n[\%])\end{array}$ \\
\hline Hypoxic or ischaemic & $62(21.7)$ & $33(53.2)$ & $29(46.8)$ \\
Metabolic or septic & $45(15.7)$ & $28(62.2)$ & $17(37.8)$ \\
Focal cerebral & $56(19.6)$ & $26(64.3)$ & $20(35.7)$ \\
General cerebral & $22(7.7)$ & $17(77.3)$ & $5(22.7)$ \\
Drug-induced/toxic & $101(35.3)$ & $92(91.1)$ & $9(8.9)$ \\
\hline
\end{tabular}

evaluation scales. The latter scale has also attracted attention because of its simplicity.

In view of the experience with these scales in traumatic coma, we conducted a comparative study in nontraumatic coma. The need for accurate prediction of mortality in nontraumatic coma by GCS was identified by Plum and Levy in 1978 [18]. In their comparison of GCS with other neurological tests, Levy et al [19] demonstrated that the GCS has good predictive value. A number of studies $[13,20-26]$ have emphasized the importance of aetiology, which, together with GCS, represents a good combination for better prediction of mortality. In our work, we have also observed the prognostic value of individual elements of the electrocardiogram in coma following cerebrovascular accident and organophosphate poisoning. Romera [27] demonstrated that GCS score correlates with APACHE II score in patients who have suffered a cerebrovascular accident; also, the former is simpler and has fewer parameters. It was concluded that GCS was, because of its simplicity and rapidity, a better scale than the Simplified Acute Physiology Score for prediction of mortality in patients with cerebroventricular accident. Kriger et al [28] identified a correlation between intracranial pressure, analyses of evoked potentials and GCS score, regardless of aetiology of coma. Those investigators also concluded that GCS is a good prognostication tool, as compared with other, more complicated methods.
Figure 2

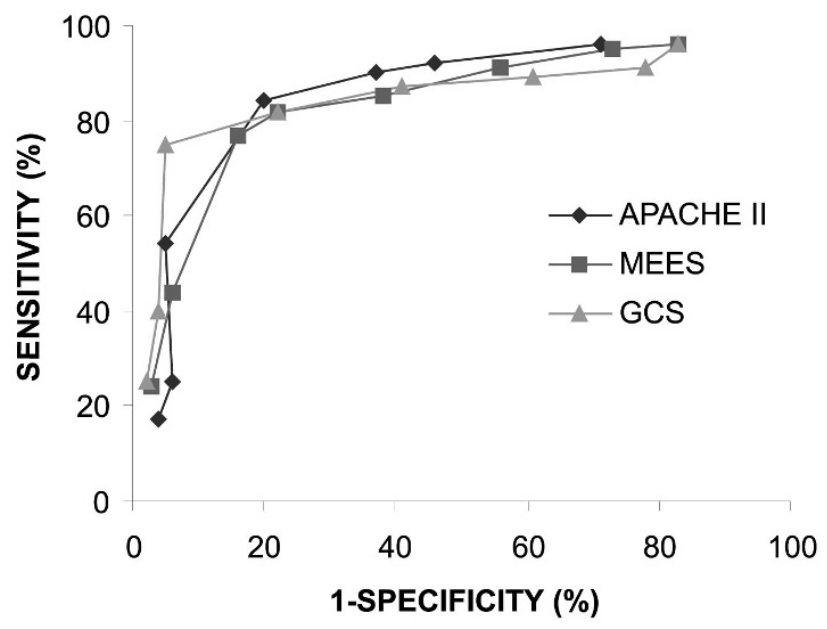

ROC curves drawn at different cutoff values for APACHE II, MEES and GCS. The area under the curve for GCS is largest, but there is no statistically significant difference when compared with APACHE II and MEES.

In the present study, coma patients were grouped on the basis of aetiology, according to the method of Sacco et al [13]. No statistically significant differences in accuracy of prognosis prediction were identified for the three scales assessed. For prehospital work, this finding is important because it shows that GCS does not deviate significantly either from the MEES scale (which has more parameters) or from the APACHE II scale (which is measured in hospital). GCS has important advantages over other scales, because it enables rapid evaluation of status and may direct necessary interventions. Furthermore, it is possible to observe continuously the state of consciousness, and to identify eventual improvement (indicating efficacy of therapy) or deterioration. GCS is widespread and clinicians are familiar with it. This scale therefore facilitates good 'clinical communication' between prehospital work and further hospital procedures and treatments.

Table 3

\begin{tabular}{|c|c|c|c|c|c|c|}
\hline Scale & Best cutoff point & Sensitivity (\%) & Specificity (\%) & $\begin{array}{l}\text { Correct prediction } \\
\text { of outcome }(\%)\end{array}$ & Youden index & ROC area \\
\hline APACHE II & 19 & 89.8 & 76.3 & 79.9 & 0.63 & $0.86 \pm 0.02$ \\
\hline MEES & 18 & 72.9 & 86.4 & 78.3 & 0.61 & $0.84 \pm 0.06$ \\
\hline GCS & 5 & 68.9 & 87.2 & $81.9^{\star}$ & 0.65 & $0.88 \pm 0.03^{\dagger}$ \\
\hline
\end{tabular}

${ }^{\star} P=0.87$ versus APACHE $\|, P=0.81$ versus MEES; ${ }^{\dagger} P=0.91$ versus APACHE $\|, P=0.90$ versus MEES. 
The GCS values determined before hospitalization of the patients and the APACHE II scores determined on the first day of hospitalization enabled us to compare descriptive and prognostic scales directly. We compared the prognostic value of postintervention prehospital values of GCS and hospital values of APACHE II. We found that the prehospital GCS assessment was as good a predictor of mortality as was the APACHE II score, as measured in the hospital. The GCS is well established, and its simple application before admission to hospital and during hospital treatment facilitates continuous evaluation of the patient's state and allows prognostic evaluation in nontraumatic coma.

\section{References}

1. Teasdale G, Jennet B: Assessment of coma and impared consciousness: a practical scale. Lancet 1974, ii:81-84.

2. Levy DE, Bates D, Caronna JJ, Cartlidge NE, Knill-Jones RP, Lapinski $\mathrm{RH}$, Singer $\mathrm{BH}$, Shaw DA, Plum F: Prognosis in nontraumatic coma. Ann Intern Med 1981, 94:293-301.

3. Jensen $M$, Neunzig HP, Emskotter T: Outcome prediction in comatose patients: significance of refex eye movement analysis. J Neurol Neursurg Psychiatry 1987, 50:389-392.

4. Starmark JE, Holmgren E, Stalhammar D: Current reporting of responsiviness in acute cerebral disorders: a survey of the neurosurgical literature. J Neurosurg 1988, 69:692-698.

5. Edgren E, Hedstrand U, Nordin M, Rydin E, Ronquist G: Prediction of outcome after cardiac arrest. Crit Care Med 1987, 15:820-825.

6. Jennett B, Teasdale G, Braakman R, Minderhoud J, Heiden J, Kurze T: Prognosis of patients with severe head injury. Neurosurgery 1979, 4:283-289.

7. Knaus WA, Zimmerman JE, Wagner DP, Draper EA, Lawrence DE: APACHE - acute physiology and chronic health evaluation: a physiologically based classification system. Crit Care Med 1981, 9:591-597.

8. Knaus WA, Draper EA, Wagner DP, Zimmerman JE: APACHE II: a severity of disease classification system. Crit Care Med 1985, 13:818-829.

9. Le Gall JR, Loirat P, Alperovitch A, Glaser P, Granthil C, Mathieu $\mathrm{D}$, Mercier P, Thomas R, Villers D: A simplified acute physiology score for ICU patients. Crit Care Med 1984, 12:975-977.

10. Chang RWS: Individual outcome prediction model for intensive care units. Lancet 1989, ii:143-146.

11. Knaus WA, Le Gall JR, Wagner DP, Draper EA, Loirat $P$, Campos RA, Cullen DJ, Kohles MK, Glaser P, Granthil C, Mercier P, Nicolas F, Nikki P, Shin B, Snyder JV, Wattel F, Zimmerman JE: A comparasion of intensive care in the U.S.A and France. Lancet 1982, ii:642-646.

12. Hennes HJ, Reinnhardt T, Dick W: The Mainz Emergeny Evluation Scoring for assessment of emergency patients [in German]. Emerg Med 1992, 18:130-136.

13. Sacco RL, VanGool R, Mohr JP, Hauser WA: Nontraumatic Coma: GCS and coma etiology as predictors of 2-week outcome. Arch Neurol 1990, 47:1181-1185.

14. Cho DY, Wang YC: Comparasion of the APACHE III, APACHE II and Glasgow Coma Scale in acute head injury for prediction of mortality and functional outcome. Intensive Care Med 1997, 23:77-84.

15. Youden WJ: Index for rating diagnostic tests. Cancer 1950, 3: 32-35.

16. Hanley JA, McNeil BJ: The meaning and use of the area under a receiver operating characteristic (ROC) curve. Radiology 1982, 143:29-36.

17. McNeil BJ, Hanley JA: Statistical approach to the analysis of receiver operating characteristic (ROC) curve. Med Decis Making 1984, 4:137-139.

18. Plum F, Levy DE: Predicting prognosis in coma: can one improve medical decisions? Am J Med 1978, 65:224-226.

19. Levy DE, Bates D, Caronna JJ, Cartlidge NE, Knill-Jones RP, Lapinski RH, Singer BH, Shaw DA, Plum F: Prognosis in nontraumatic coma. Ann Intern Med 1981, 94:293-301.
20. Bates D, Caronna JJ, Cartlidge NEF, Knill-Jones RP, Levy DE, Shaw DA, Plum F: A prospective study of nontraumatic coma: methods and results in $\mathbf{3 1 0}$ patients. Ann Neurol 1977, 2: 211-220.

21. Portenoy RK, Lipton RB, Berger AR, Lesser ML, Lantos G: Intracerebral hemorrhage: a model for prediction of outcome. $J$ Neurol Neurosurg Psychiatry 1987, 50:976-979.

22. Mullie A, Verstringe $P$, Buylaert $W$, Houbrechts $H$, Michem $N$, Delooz H, Verbruggen $\mathrm{H}$, Van den Broeck L, Corne L, Lauwaert D, et al: Predictive value of the Glasgow coma score for awakening after out-of-hospital cardiac arrest. Lancet 1988, i:137140.

23. Levy DE, Caronna JJ, Singer $\mathrm{BH}$, Lapinski $\mathrm{RH}$, Frydman $\mathrm{H}$, Plum F: Predicting outcome from hypoxic-ischemic coma. JAMA 1985, 253:1420-1426.

24. Snyder BD, Loewenson RB, Gumnit RJ, Hauser WA, Leppik IE, Ramirez-Lassepas M: Neurologic prognosis after cardiopulmonary arrest, II: level of consciousness. Neurology 1980, 30: 52-58.

25. Emerman CL, Connors AF, Burma GM: Level of consciousness as a predictor of complications following tricyclic overdose. Ann Emerg Med 1987, 16:326-330.

26. Stanczak DE, White JG III, Gouview WD, Moehle KA, Daniel M, Novack T, Long CJ: Assessment of level of consciousness following severe neurological insult. J Neurosurg 1984, 60:955960.

27. Romera E: Prognosis of stroke patients admited to the ICU [abstract]. Intensive Care Med 1997, 23:162.

28. Kriger D, Adams HP, Schwarz S: Prognostic and clinical revelance of pupillary response, intracranial monitoring and brainstem auditory evoked potentials in comatose patients. Crit Care Med 1993, 47:1181-1184. 